\title{
PARO JUVENIL O DESIGUALDAD ${ }^{1}$
}

\section{Luis J. Garrido Medina UNED}

\begin{abstract}
RESUMEN
Se plantea el paro como una de las consecuencias de la forma institucional en la que la sociedad española (como parte de la europea) ha incorporado las mejoras de su calidad de vida. En contra de la opinión más extendida, se observa que, durante las tres últimas décadas, el sistema productivo ha expulsado de la ocupación a más trabajadores mayores que jóvenes. Tras unas consideraciones sobre el cambio de posición laboral de la mujer debido a la Revolución Reproductiva, al considerar el paro y la ocupación de los que ya han terminado los estudios se aprecia que el enorme incremento de dedicación a la formación de los jóvenes españoles coloca a los más cualificados en una posición de clara ventaja respecto a sus coetáneos, contradiciendo las conclusiones del conocido modelo mediterráneo de integración laboral. Se estudia la relación entre la política de contratación temporal y el acceso de los jóvenes al primer empleo, dejando en evidencia el desbloqueo de la primera integración al que dio lugar. La disminución drástica de puestos de trabajo de bajo nivel representa, más allá de la conocida reconversión industrial, una auténtica reconversión social. Finalmente, se apuntan unas posibles líneas de actuación para mejorar la integración laboral de los jóvenes.
\end{abstract}

${ }^{1}$ Este trabajo tiene como origen el estudio promovido por la Organización Internacional del Trabajo, con sede en Ginebra, publicado en Luis GARRIDO (1995), Diagnóstico sobre el paro juvenil y políticas para facilitar la entrada al primer trabajo, Colección "Estudios de Políticas», núm. 16, OIT, Ginebra. Para su inserción en el marco más amplio de la integración social de los jóvenes puede verse Luis GARRIDO y Miguel REQUENa (1996), La Emancipación de los jóvenes en España, Injuve, Madrid, resultado de la investigación financiada por el Instituto Nacional de la Juventud. 


\section{INTRODUCCION}

Durante los dos últimos decenios, el problema del desempleo ha surgido y se ha agravado en España por un conjunto de causas entre las que destacan la evolución demográfica, la transformación de los sectores de actividad, las sucesivas crisis económicas (que aquí se convirtieron en crisis de empleo por la reestructuración productiva que propiciaron), el retorno de los emigrantes y la conversión en país receptor, el cambio de posición social de la mujer, la notable disminución de la cantidad de puestos de trabajo en las ocupaciones de bajo nivel y algunas dificultades de adaptación al rápido crecimiento del Estado del Bienestar que se suelen formular como rigideces institucionales.

En general, se puede afirmar que el paro es en gran medida uno de los efectos no deseados de los progresos en la calidad de vida de los españoles. Así, puede considerársele como un coste indirecto de la forma en que la sociedad ha incorporado esas mejoras sociales y económicas. Es posible que la aceptación por parte de la ciudadanía del alto nivel de paro esté relacionada con la conciencia de que éste es consecuencia de unos cambios cuyo saldo global resulta ventajoso para la mayoría de la población.

En la perspectiva que aquí se adopta, el sistema productivo (en su dimensión de conjunto de puestos de trabajo) sobredetermina la utilización del capital humano como conjunto de trabajadores potenciales. Por lo tanto, el problema de la inserción laboral de los jóvenes es, antes y de forma más determinante, un efecto de la incapacidad del sistema socioeconómico para generar suficiente cantidad de puestos de trabajo, que un problema de acoplamiento entre el sistema formativo y el productivo.

No se quiere decir con esto que no se pueda mejorar el ajuste entre la educación y el empleo, pero estas mejoras no pueden curar la problemática inserción de los jóvenes en el trabajo. A pesar de ello, su carácter no es exclusivamente paliativo ya que, sobre todo a largo plazo, el enriquecimiento formativo y su mejor aplicación a la producción transforman el sistema productivo en cierta medida. Las políticas que se adopten para mejorar el ajuste entre la formación y el empleo deben partir de una toma en consideración de las causas estructurales del desempleo general y de la forma en que su génesis y su estructura afectan a las dificultades de los jóvenes para encontrar su primer empleo.

\section{LA OCUPACION DE LOS JOVENES Y LA DE LOS MAYORES: ¿QUIENES PIERDEN MAS?}

La situación de los jóvenes en el mercado de trabajo ha padecido las diferencias que se deducen de su específica posición en el ciclo de vida laboral. La entrada en cualquier espacio social con excedentes es lógico que conlleve dificultades porque cuando los puestos están ocupados la cola de acceso crece. 
El mercado de trabajo puede interpretarse como un canal ${ }^{2}$ que procesa personas con una entrada y una salida. Los jóvenes ingresan en él "cuando están preparados" y los mayores lo abandonan "cuando ya han cumplido". Cuando un canal se llena hasta la saturación, se bloquea y no es capaz de dar entrada a todos los que lo desean. Para resolver esa saturación procede a expulsar a los sobrantes, al tiempo que no permite la entrada de todos los que intentan acceder a él. Para comprender en un sentido cabal si los jóvenes están en mejor o peor situación que sus antecesores no se les debe comparar con los que permanecen en el canal, sino que hay que poner en relación a los que entran con los que salen.

Si el canal expulsa a los que estaban en posiciones cercanas a su salida en proporciones menores que aquellas en las que impide entrar a los que se acercan a su entrada se podrá hablar de que los entrantes están en peor situación que los salientes. Otro sería el caso en el que los entrantes presionan con tal eficacia que desplazasen incluso a los que están alejados de los puestos de salida. Aunque los ciclos de vida laboral son diferentes para las diferentes ocupaciones (por ejemplo, los deportistas se jubilan jóvenes y, entre ellos, los gimnastas tienen un ciclo más corto que, por ejemplo, los golfistas), la edad es un indicio estadísticamente compacto para definir la posición en el ciclo de vida laboral ${ }^{3}$.

Normalmente, para comparar esas situaciones se utiliza la proporción de los que no están en la situación que quisieran. Con respecto al mercado de trabajo, los que están típicamente en esa posición son los que quieren trabajar (voluntad que expresan con la búsqueda de trabajo) y no lo hacen porque no encuentran un trabajo que les convenga; en una palabra: los parados. Pero el paro (como índice de esta contradicción de la voluntad) tiene un inconveniente, y es que mientras que los jóvenes buscan trabajo incluso cuando no podrían dedicarse a él debido a sus estudios, los mayores saben que si son despedidos no van a encontrar otro trabajo. Y si no lo van a encontrar, ¿para qué buscarlo?

La realidad de esta diferencia de respuestas se aprecia en la bajada de actividad de los mayores, mientras que los jóvenes la mantienen en mucha mayor medida. En 1969 los varones de 25 a 29 años tenían una actividad del 94,6 por 100 y los de 55 a 59 años del 91,3 por 100. Actualmente (II/1994) los de

${ }^{2}$ En un sentido semejante al de los canales de comunicación que procesan la información que fluye a través de ellos.

${ }^{3}$ Un elemento adicional de comparación sería la productividad de los empleados. El canal debiera procesar a los trabajadores incorporando a los más productivos y dando salida a los que lo son menos. La experiencia de los ocupados desequilibra en su favor esta diferencia. Sin embargo, los jóvenes en España cuentan con la ventaja de un nivel medio de cualificación formal muy superior al de sus antecesores, sobre todo respecto a los de más edad, que son los más cercanos a la salida. La contradicción se acentúa porque esos jóvenes con mayor formación tienen que entrar, como corresponde al principio de su carrera, por los puestos más bajos. Como no tenemos acceso a información sobre distribución por edades de la productividad, se supone provisionalmente que estos elementos se contrarrestan y con ello se neutralizan, por lo que se pueden comparar simplemente las edades de entrada con las de salida. 
25-29 la mantienen en el 90,1 por 100, mientras que los de 55-59 han bajado hasta el 72,8 por 100 . Si ambos grupos hubiesen mantenido hasta $1994 \mathrm{su}$ actividad al nivel de 1969 , los jóvenes tendrían un 29,8 por 100 de paro y los mayores un 33,5 por 100 , luego los mayores han salido en mayor medida. Sin embargo, con el cambio de actividad que efectivamente se ha producido, los jóvenes (25-29) tienen en 1994 un paro del 26,3 por 100 y los mayores (5559) un 16,7 por 100 , con lo que parece que los mayores están en mejor posición, cosa que, como se ha visto, no es cierta.

El desánimo de los mayores queda reflejado en el hecho de que el paro de los varones de 60 a 64 años es del 9,7 por 100, a pesar de que en 1994 están trabajando únicamente el 38 por 100 de todos ellos. ¿Tendría sentido suponer que en 1994 están parados el 53 por 100 del grupo de 60-64 años sólo porque en 1969 trabajaban el 81 por 100 ?

Para poder efectuar esta comparación sin dichos inconvenientes se puede observar la evolución de las proporciones de ocupados en posiciones de entrada con las de los que están en edades de salida. El gráfico 1 deja en evidencia la más que notable similitud entre la evolución de la ocupación por pares de grupos de edad ${ }^{4}$. Se observan únicamente los varones porque el cambio de biografía laboral de la mujer en España es de tal envergadura que no permite este tipo de comparaciones.

Unicamente en los años de la crisis del petróleo (1976-1985) padecieron los dos grupos más jóvenes (el de 16-19 y, en mayor medida, el de 20-24) más dificultades de incorporación al trabajo que las que tuvieron sus mayores para mantenerse en sus puestos de trabajo. La recuperación del empleo (contenida en el gráfico 1 entre el IV/1984 y el IV/1989) benefició a los jóvenes en mucha mayor medida que a los mayores, con lo que se compensó la desventaja anterior. La nueva crisis perjudica algo más a los jóvenes, pero no lo suficiente como para que no terminen el período en igualdad de condiciones respecto a sus correspondientes mayores. Como saldo de todo el período, los jóvenes no han padecido en mayor medida que los mayores las estrecheces del mercado laboral.

La diferencia entre las distintas edades debe ser interpretada en términos de las alternativas que se les ofrecen a los no aceptados y a los expulsados por

${ }^{4}$ La simetría se establece tomando como extremos los grupos de 16-19 años y de 65-69, de modo que las otras parejas de edades sean 20-24 años con 60-64 y 25-29 años con 55-59. El criterio consiste en definir su posición de entrada o salida por la proporción de ocupados respecto al total de la población de esa edad. Estarán en la misma posición los que tengan un porcentaje de ocupación semejante. El que no se puedan obtener los datos de las edades año a año (en lugar de por grupos quinquenales) hace que la semejanza no sea muy ajustada, sobre todo en los grupos extremos, a lo que hay que añadir el hecho de que a partir de 1976 el grupo de 15-19 años pasa a ser de 16-19 debido al cambio de legislación. La progresiva desaparición de los trabajadores adolescentes ha llevado las proporciones de ocupación a los 16 años a un 7 por 100 para los varones y a un 3 por 100 para las mujeres. En 1976 eran de un 50 y un 48 por 100, respectivamente. Si el grupo se conservase en los 15-19 años, la semejanza de su evolución con la de los 65-69 años sería mayor. 


\section{GRAFICO 1}

Evolución de la ocupación de los varones entre 1964 y 1994 (Porcentaje de ocupados respecto a la población total en cada grupo de edad)

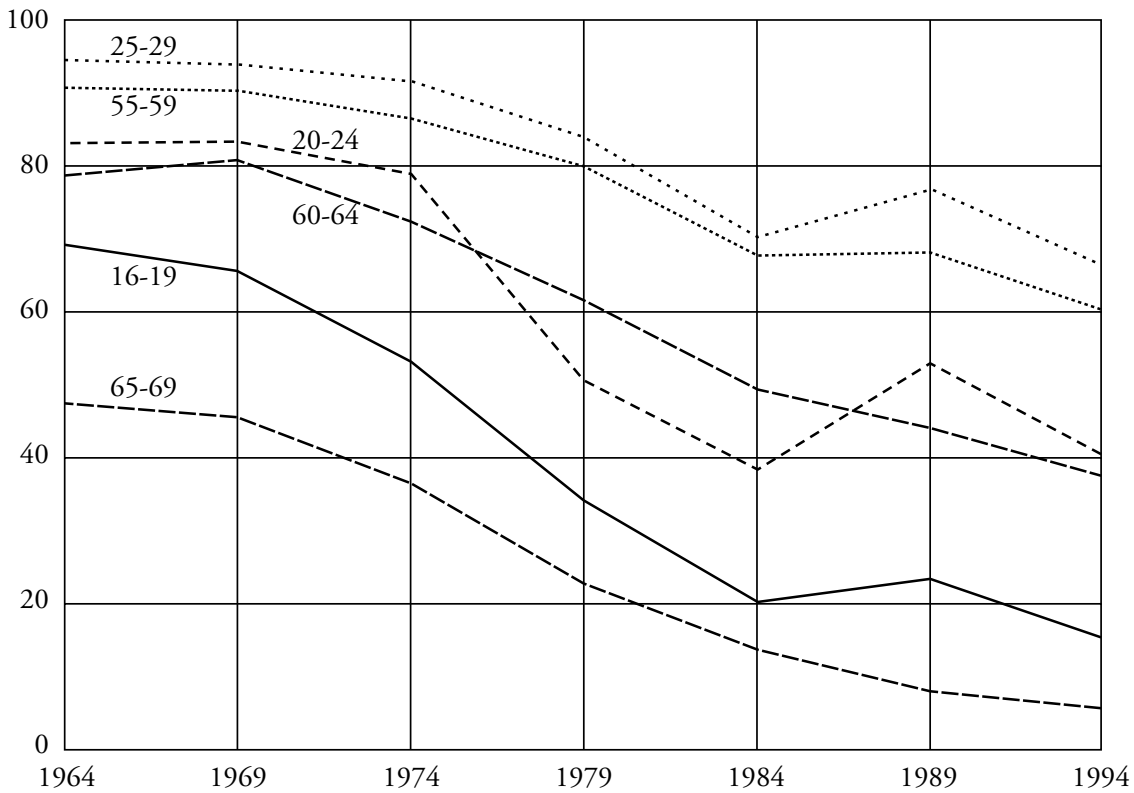

FuENTE: EPA, cuartos trimestres.

el sistema productivo. Mientras que la protección de las jubilaciones aumenta la autonomía objetiva de los mayores, a los jóvenes tanto la prolongación de los estudios como los largos períodos de búsqueda del primer empleo les mantienen en la dependencia familiar. La única opción práctica de los adultos es el desempleo, cubierto temporalmente por las prestaciones contributivas y posteriormente por las asistenciales. Cuando se acaban las prestaciones, e incluso mucho antes, la situación de los parados adultos se hace socialmente inviable si no hay apoyo familiar.

El estudio de las edades centrales (la ocupación de los varones adultos no aparece en el gráfico 1) permite afirmar que durante la última crisis la proporción entre sus pérdidas de ocupación y las de los jóvenes aumentó de modo que se puede hablar de un reparto más igualitario de los efectos de la disminución del empleo, lo que significa una ventaja comparativa importante para los jóvenes y, probablemente, un problema social y económico más complejo que el ya difícil del paro juvenil y la expulsión de los mayores. 


\section{LA POSICION LABORAL DE LA MUJER}

En 1976 nacieron 683 mil españoles; en 1994, 353 mil. De este impresionante descenso de la natalidad parecería deducirse un horizonte de próxima disminución del crecimiento de la población activa cuando comiencen a incorporarse al mercado estas generaciones más reducidas que las precedentes. Dado que la edad de ingreso en el mercado de trabajo esta fijada en los 16 años, se debería empezar a apreciar, a partir de 1993, el descenso en la incorporación de los jóvenes al trabajo como consecuencia de la disminución de la población. Los datos, sin embargo, parecen desmentir este supuesto. La causa hay que buscarla en el cambio de posición laboral de la mujer.

Uno de los logros más incontestables de los humanos es el que consiste en alargar su propio tiempo de vida. La liberación de una parte sustancial del tiempo dedicado a la reproducción ha dado lugar a una mayor disposición de tiempo activo, que se concreta en la incorporación (o, más exactamente, la consolidación) de la mujer en el trabajo extradoméstico. Esta consolidación tiene el efecto de incrementar la proporción de la población disponible para trabajar.

Una interpretación sociohistórica consistiría en entender el cambio de posición de la mujer como la consecuencia de un cambio sectorial de estructura semejante al de la revolución industrial o al de la revolución de los servicios producto de la sociedad postindustrial. Con la disminución de la mortalidad y la tecnificación del hogar, el sector de la reproducción (generación, crianza y mantenimiento de los humanos) ha aumentado de una forma radical su productividad, al tiempo que la prolongación de la vida disminuía la demanda de nacimientos. Esta revolución reproductiva ha expulsado a otros sectores a una gran parte de sus efectivos, formados en su mayoría por mujeres. La asunción parcial por el Estado del Bienestar de estas tareas ha incrementado aún más la productividad, dando lugar a una causación circular acumulativa. Los excedentes del sector reproductivo no han encontrado fácil acomodo en los demás sectores del sistema productivo cuando las reglamentaciones laborales dificultaban el trabajo a tiempo parcial o la contratación de servicios personales a precios inferiores a la media.

Aunque en España (en términos cuantitativos globales) parece que el aumento de la participación de la mujer en el sistema productivo no es importante, la comparación de la trayectoria típica de las trabajadoras de hace veinte años con las actuales deja en evidencia una sustitución generalizada. De forma resumida, se puede afirmar que en España se han sucedido dos biografías laborales de la mujer ${ }^{5}$. La primera es mayoritaria entre las que en 1995 tienen más de 45 años y la segunda entre las más jóvenes de esa edad.

Durante el desarrollo (1965-1974) la pauta generalizada era el trabajo en la

Luis Garrido Medina (1992), Las dos biografias de la mujer en España, Instituto de la Mujer, Ministerio de Asuntos Sociales, Madrid. 
primera juventud (16-23 años de edad) como asalariadas en el sector privado de baja cualificación, para luego casarse y pasar a colaborar en los negocios familiares (agricultura, hostelería y comercio). Con esta pauta, la vida típica media de la mujer asalariada tenía una duración aproximada de seis años y estaba centrada en la edad de 21 años (a esta edad, en 1974 estaban ocupadas más del 60 por 100 de las jóvenes). En la actualidad, la vida típica media para gran parte de las jóvenes-adultas asalariadas es predeciblemente semejante a la de sus coetáneos varones (superior a 40 años) y su máximo se centra (transitoriamente) en los 28 años de edad. Sin embargo, la intensidad de su participación no es muy alta puesto que la tasa de ocupación no supera el 45 por 100 a ninguna edad. La media de cualificación de estas ocupadas es sensiblemente superior a la de los varones y su mayoritaria integración en el sector público se realiza en niveles progresivamente más elevados.

Las nuevas mujeres trabajadoras no se retiran al casarse $y$, entre las cualificadas, tampoco lo hacen al cumplir su reducida maternidad, por lo que su incorporación al mercado de trabajo es acumulativa, ya que se suman con las que vendrán después. Esto será así al menos durante las dos próximas décadas, a partir de las cuales empezarán a jubilarse y se igualarán los flujos de entrada y de salida de las mujeres. Como consecuencia de este embolsamiento de actividad femenina, la tasa global de actividad y la cantidad total de activos seguirá creciendo en España durante los próximos años, a pesar de que la evolución demográfica pronostica un cierto descenso ${ }^{6}$ de población potencialmente activa (de 16 a 64 años de edad). Otro efecto del cambio de posición laboral de la mujer es el incremento de la asalarización de la fuerza de trabajo.

\section{LA FORMACION PARA EL EMPLEO}

El incremento espectacular de la dedicación a los estudios de los jóvenes españoles (y más aún el de la mitad femenina) es un efecto de varias causas, entre las que destacan precisamente las relacionadas con los cambios en los mercados matrimonial y de trabajo. El bloqueo a la incorporación de los jóvenes al empleo que se produjo entre los años 1979-1985 dio lugar a que la opción por los estudios se convirtiese en la forma más razonable de ocupar e invertir el forzado tiempo de espera. Esto fue así en mayor medida para las mujeres. De los tres campos convencionales de dedicación: a la producción (empleo), a la reproducción (familia y maternidad) y a la autoproducción (for-

${ }^{6}$ Esta disminución no es tan inmediata como en un principio se podría suponer ya que las entradas de jóvenes no son significativas hasta los 20 años de edad, que es cuando se alcanza una tasa de actividad del 50 por 100 . Por otra parte, las cohortes menguadas como consecuencia de la escasa natalidad causada por la guerra civil están actualmente centradas en los 54 años de edad y pasarán a jubilarse en los próximos años, por lo que al tiempo que disminuyen las entradas lo harán también las salidas de la actividad, con lo que el saldo total será menos negativo de lo que se supone al observar únicamente la evolución de las incorporaciones. 
mación profesional), las dos primeras estaban cerradas por la casi imposibilidad, tanto para ellas mismas como para los improbables e insolventes maridos, de encontrar un trabajo. En estas condiciones la opción por la continuación de los estudios aparecía como la única alternativa a un vacío de ocupación concreta, en situación de hija perpetua, que, más que inactividad, se podría denominar parálisis. El éxito individual relativo en el logro de trabajo al que dan lugar los estudios hace que se generalice la opción por continuar los estudios.

Si se observan las proporciones de estudiantes entre los jóvenes españoles parece que han entendido el mensaje: "Hay que continuar los estudios para eludir el paro». Los estudios no sólo se prolongan en el sentido del acceso sucesivo y continuo a los niveles superiores, sino que se continúan en el mismo nivel cuando no se consiguen buenos resultados e incluso, cuando se han abandonado, se retoman posteriormente, alargando de una manera notable esta parte del ciclo vital. El importante contingente de jóvenes (cerca de 400 mil) que se dedica a preparar oposiciones para hacerse funcionario en las administraciones del Estado extiende aún más el amplio margen de edades de los estudiantes españoles.

Esta hipereducación de una generación en relación a las anteriores no va a lograr revolucionar a corto plazo la estructura ocupacional. Lo que puede conllevar de forma inmediata es la frustración y posibles deficiencias en la dimensión profesional de la formación de una parte importante de la población. Tanto desde el punto de vista social como del económico, un ingeniero o un gerente de gran empresa no son personas que han estudiado para poder ejercer esas profesiones, sino que son individuos que ocupan realmente esos puestos de trabajo concretos. Desde esta perspectiva, las dificultades de previsión sobre la estructura ocupacional no deberían aminorar los esfuerzos encaminados a un mayor conocimiento de su estructura y de su dinámica. Es indispensable estudiar la influencia de la oferta de trabajadores cualificados en el esquema de requerimientos de formación en situaciones de sobreoferta. Un sistema formativo que se rige largo tiempo por la oferta es altamente probable que no logre ajustarse a la demanda, por muchos esfuerzos corporativos que haga para condicionarla.

Con esto no se pretende poner en cuestión la validez de la educación entendida en el sentido más amplio posible. En España es característica la ignorancia tecnológica, que no ayuda en absoluto a relacionarse con los aparatos, y a todos los ciudadanos les sería también muy conveniente saber siquiera los fundamentos jurídicos y económicos del funcionamiento social para poder adaptarse mejor a una sociedad progresivamente compleja. Lo que aquí se critica es la validez, por ejemplo, de una enseñanza superior de ingeniería aeronáutica para que su destinatario se dedique a llevar la contabilidad de una empresa y sus profundos conocimientos tecnológicos vayan envejeciendo en el vacío de lo inútil, ya que sólo le sirven para manejar con mayor nivel de conciencia los electrodomésticos. Para que progrese un país es prioritaria la transformación del sistema socioproductivo. 
Pero, aparte de las consideraciones generales, parece pertinente poner en cuestión alguno de los tópicos sobre la relación entre los niveles de formación y los de integración efectiva en el empleo. Para ello puede ser útil alguna consideración previa sobre el uso del índice de desempleo.

Aunque es conocida la atención generalizada hacia el paro, se habrá observado que hasta aquí se ha utilizado continuamente la ocupación para definir la evolución del mercado (en número de ocupados) y para comparar (en porcentajes de ocupados respecto a la población total) las posiciones de las diferentes edades respecto a su situación laboral. Esta opción tiene como soporte la consideración del trabajo como un índice más vinculado a la realidad del sistema productivo que las expresiones sobre búsqueda de empleo por parte de personas que tienen a menudo otras ocupaciones socialmente aceptadas. No se quiere decir con esto que no sea necesaria la definición de la oferta de trabajo en términos de población activa, pero sí que su componente de paro parece reclamar una redefinición, no por difícil menos necesaria, para saber de qué hablamos cuando hablamos de parados.

A la espera de esa delimitación, parece más indicativo utilizar como índice de paro el que se podría denominar paro absoluto (o proporción absoluta de paro), definido por el porcentaje de parados respecto a la población total en edades potencialmente activas. Este índice es especialmente apropiado para las distribuciones por grupos de edad. La participación productiva de cada edad en la sociedad tiene alternativas reproductivas (la crianza y el mantenimiento de los individuos y sus domicilios) y autoproductivas (la formación). La significatividad del paro absoluto se basa en que tiene en cuenta implícitamente las opciones distintas al empleo, dando un sentido de presión laboral de cada grupo de edad más directo que el que pretende transmitir el índice convencional de paro (proporción de parados respecto a la población activa de cada grupo de edad).

Es frecuente en las comparaciones internacionales la afirmación de que en los países mediterráneos no se da una correlación negativa entre nivel de paro y nivel de estudios. Como ejemplo: "Los paises del sur de Europa constituyen el tercer grupo, en el cual las tasas de paro son más altas en el caso de las personas que tienen un nivel de estudios más alto" (OCDE, Perspectivas del empleo, 1994, 76).

La causa de la confusión obedece a que no se considera la importante prolongación de los estudios (que se incrementa cuanto mayor es el nivel alcanzado), unida también a importantes retrasos en las edades a las que se realizan esos estudios. Como muestra el gráfico 2, la extensión de los estudios a edades avanzadas es uno de los fenómenos más significativos de la juventud española. Como muestra se puede citar que a los 25 años de edad (las carreras universitarias de ciclo largo se deberían terminar a los 23 años de edad) estudian el 23 por 100 de las mujeres y el 19 por 100 de los varones.

A los que están cursando estudios no tiene sentido incluirlos en los cálculos de paro por niveles de estudios. Y esto por las siguientes razones: 


\section{GRAFICO 2}

Cursando estudios en 1976 y en 1994: porcentaje de estudiantes por sexo y edad año en año

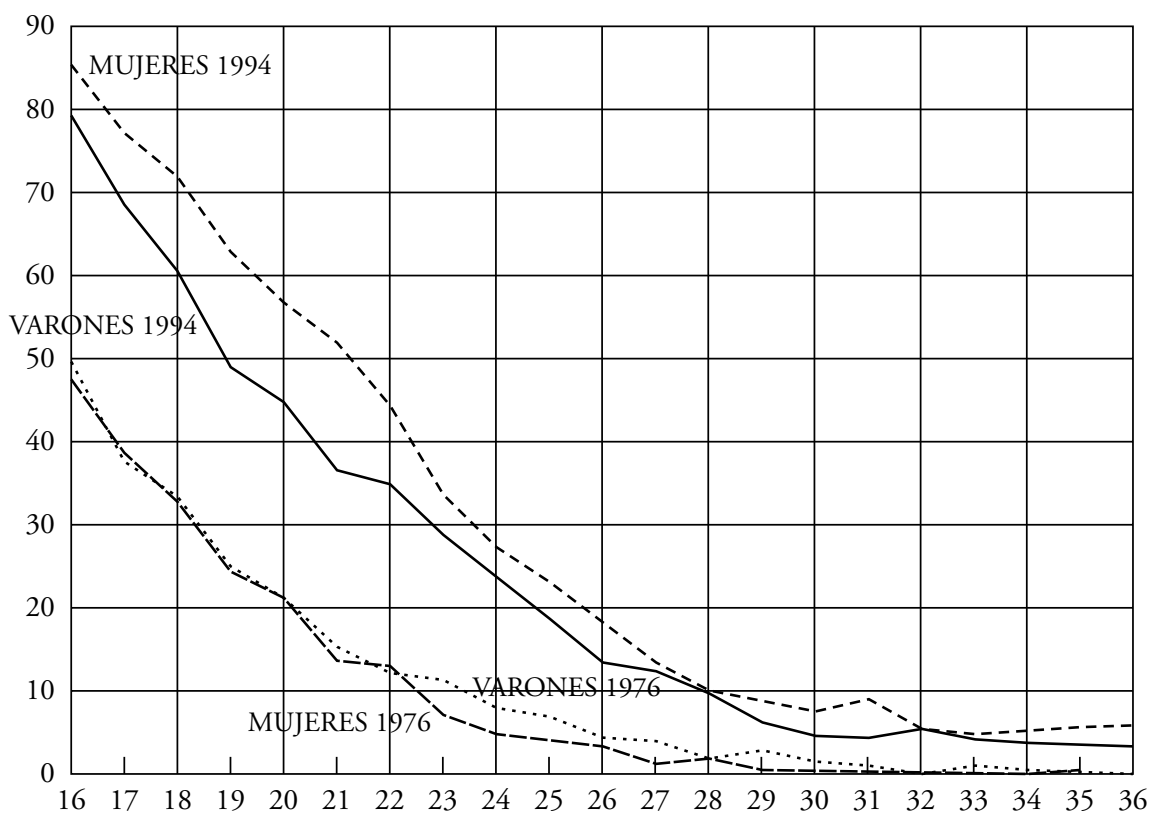

FUENTE: EPA IV/1976 y IV/1994. Se incluyen todo tipo de estudios, incluidos los opositores.

- No parece procedente considerar desocupados a quienes estudian a tiempo completo cursos de más de un año de duración, ya que ocupan suficientemente su tiempo para considerarlos socialmente ocupados (aunque no exactamente empleados).

- Se les puede considerar productivos al estar realizando una actividad autoproductiva, ya que se transforman a sí mismos en dispositivos con una mayor productividad (fabrican herramientas).

- Y no se puede considerar definitivo su nivel de estudios terminados, ya que al seguir estudiando siguen incrementando este nivel.

Por estas razones, para establecer la relación entre nivel de estudios acabados e incidencia del desempleo conviene observar únicamente a los que no cursan estudios.

Por otra parte, la incidencia del paro de quienes buscan el primer empleo se distribuye en función de la edad con una lógica biográfica (longitudinal), dependiendo del nivel máximo de estudios alcanzado. Los que buscan empleo 
con estudios primarios pueden empezar a hacerlo a partir de los 16 años, mientras que los que lo hacen después de terminar una licenciatura universitaria comenzarán su búsqueda a partir de los 23-25 años de edad. Esta distancia de nueve años (y las demás intermedias en función de los diferentes niveles y tiempos de estudios) desorienta el análisis cuando no se distingue el paro de primer empleo del paro experto al analizar su distribución por estudios. En España, este efecto es mayor porque muchos jóvenes retrasan la realización de sus estudios. Mientras «la edad laboral» de un obrero con estudios primarios nacido hace 26 años puede ser de más de diez años, esa "edad laboral», para un empleado licenciado universitario nacido el mismo año, puede no llegar a un año. Esto tiene una influencia definitiva entre los buscadores de primer empleo y casi ninguna cuando ya se logra una experiencia laboral acorde con el nivel de estudios alcanzado.

Si se utiliza el paro absoluto de primer empleo excluyendo a los que siguen cursando estudios (cantidad de parados de un cierto nivel de estudios dividida por la población de ese nivel) y se distribuye por sexo y edad, los resultados, representados en los gráficos 3 y 4 , son muy significativos. Hay una casi iden-

\section{GRAFICO 3}

Varones: porcentaje de parados de primer empleo según el nivel de estudios terminados $y$ la edad

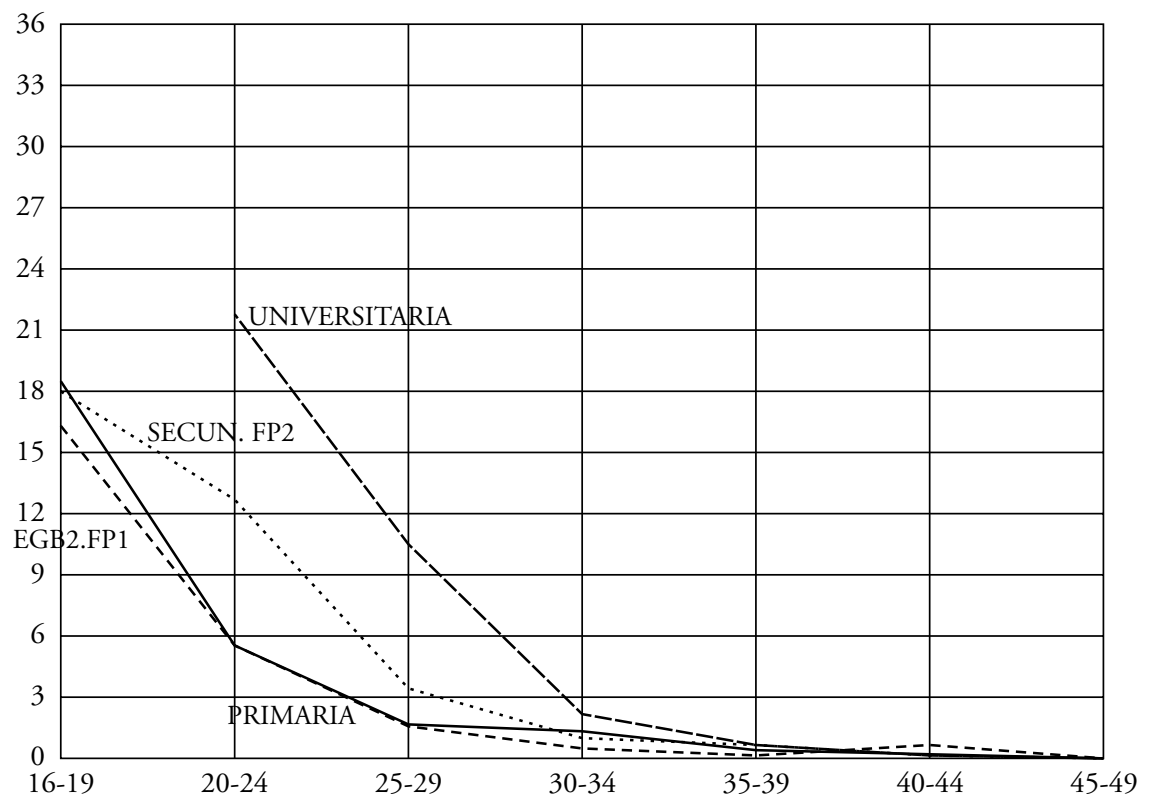

FUENTE: EPA IV/1994. Sólo se considera la población que no cursa estudios. 


\section{GRAFICO 4}

Mujeres: Porcentaje de paradas de primer empleo según el nivel de estudios terminados y la edad

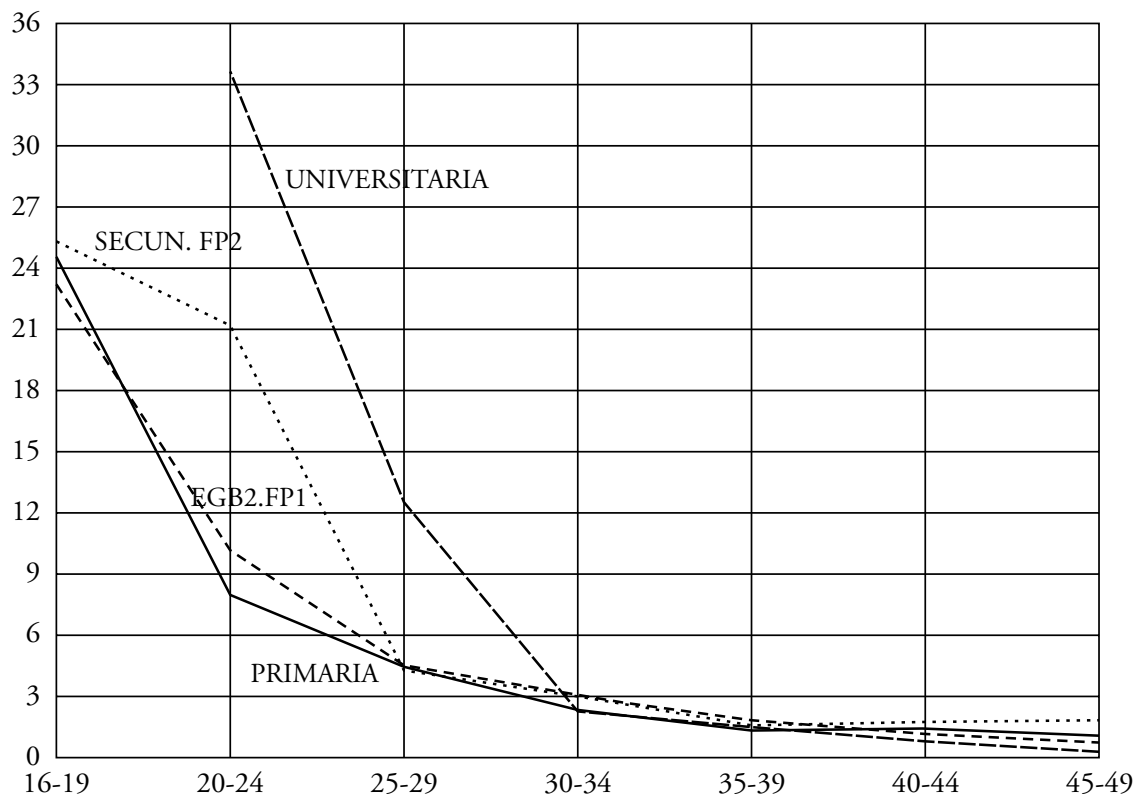

FUENTE: EPA IV/1994. Sólo se considera la población que no cursa estudios.

tidad en las proporciones de parados entre los niveles bajos de estudios que se pueden alcanzar a edades previas a las de empezar a trabajar, y que van desde los que no tienen estudios de ningún tipo hasta la secundaria obligatoria y la formación profesional de primer grado (FP1) ${ }^{7}$.

Los que tienen el BUP y el COU o la FP2 presentan unas proporciones de búsqueda del primer empleo semejantes a las de los anteriores pero desplazadas 3-4 años, que se corresponden con el tiempo que hay que añadir para finalizar estos estudios. A los universitarios, tanto diplomados como licenciados, les sucede lo mismo al cumplir tres años más.

Este tipo de formación tiene en el inmediato pasado una connotación fuertemente peyorativa puesto que era la vía por la que completaban la enseñanza obligatoria los fracasados en la Enseñanza General Básica (EGB). Esta caracterización residual, unida a la escasa dimensión profesional del aprendizaje, a los medios limitados con los que contaba y a la casi total desconexión con la experiencia concreta en los puestos de trabajo, han hecho hasta ahora de este nivel de enseñanza algo muy poco relacionado con su nombre de Formación Profesional. Por todo ello, se ha unido con la EGB2, que es la secundaria obligatoria. 
Se puede afirmar, por lo tanto, que el paro de primer empleo afecta de una manera uniforme, pero desplazada biográficamente, a los diferentes niveles de estudios de tal modo que equilibra su diferente nivel de participación laboral (actividad). Una demostración de que esta interpretación es cierta la proporciona la gran igualdad entre los diferentes niveles de estudios de la mediana del tiempo (medido en meses) que llevan buscando su primer empleo.

Una vez apartados los que cursan estudios y los que buscan el primer empleo, la observación del paro de quienes han trabajado antes deja en evidencia que cuanto menor es el nivel de estudios alcanzados, mayor es la proporción de parados, tal como expresan claramente los gráficos 5 y 6 . Si en lugar de utilizar la tasa convencional de paro usamos el paro absoluto la distribución de los varones no cambia (sólo disminuye la escala), pero la de las mujeres da una igualdad mucho mayor a excepción de las universitarias, que siguen teniendo una integración laboral más eficiente.

\section{GRAFICO 5}

Varones: Porcentaje de parados que han trabajado antes según el nivel de estudios terminados y la edad

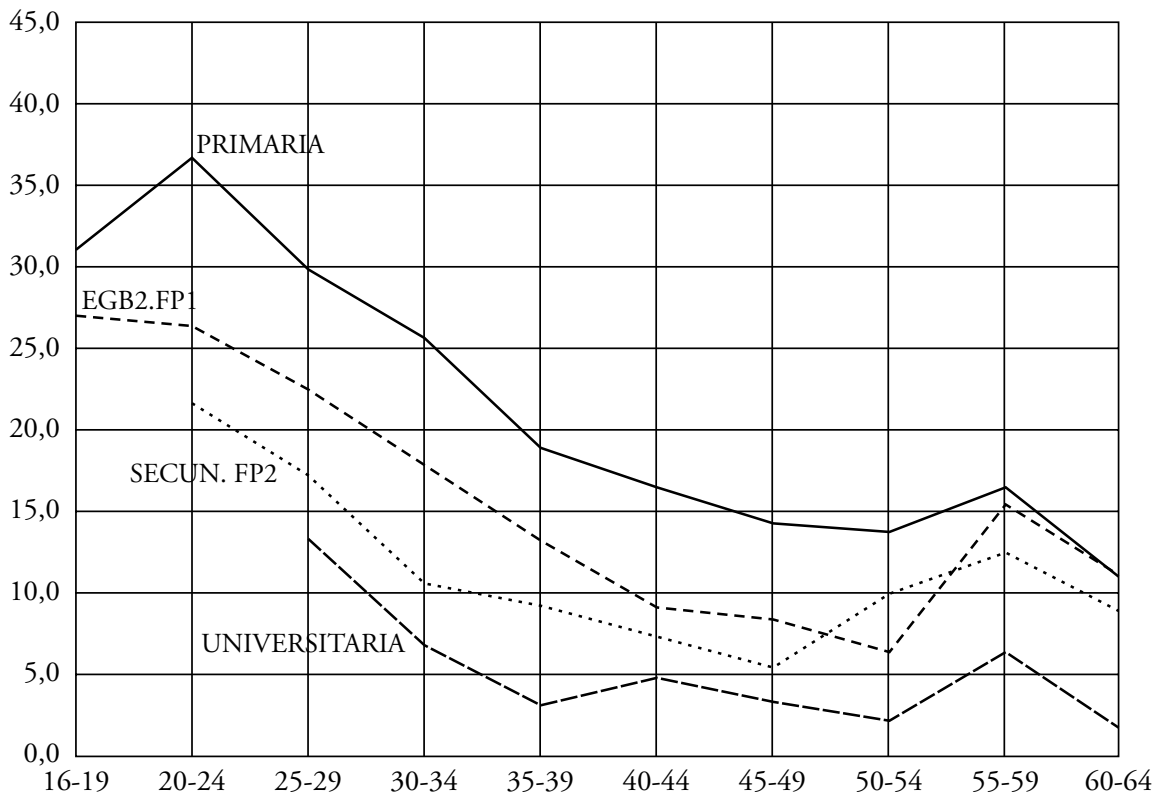

Fuente: EPA IV/1994. Como base se considera la población activa que ha trabajado antes y que no cursa estudios. 


\section{GRAFICO 6}

Mujeres: Porcentaje de paradas que han trabajado antes según el nivel de estudios terminados y la edad

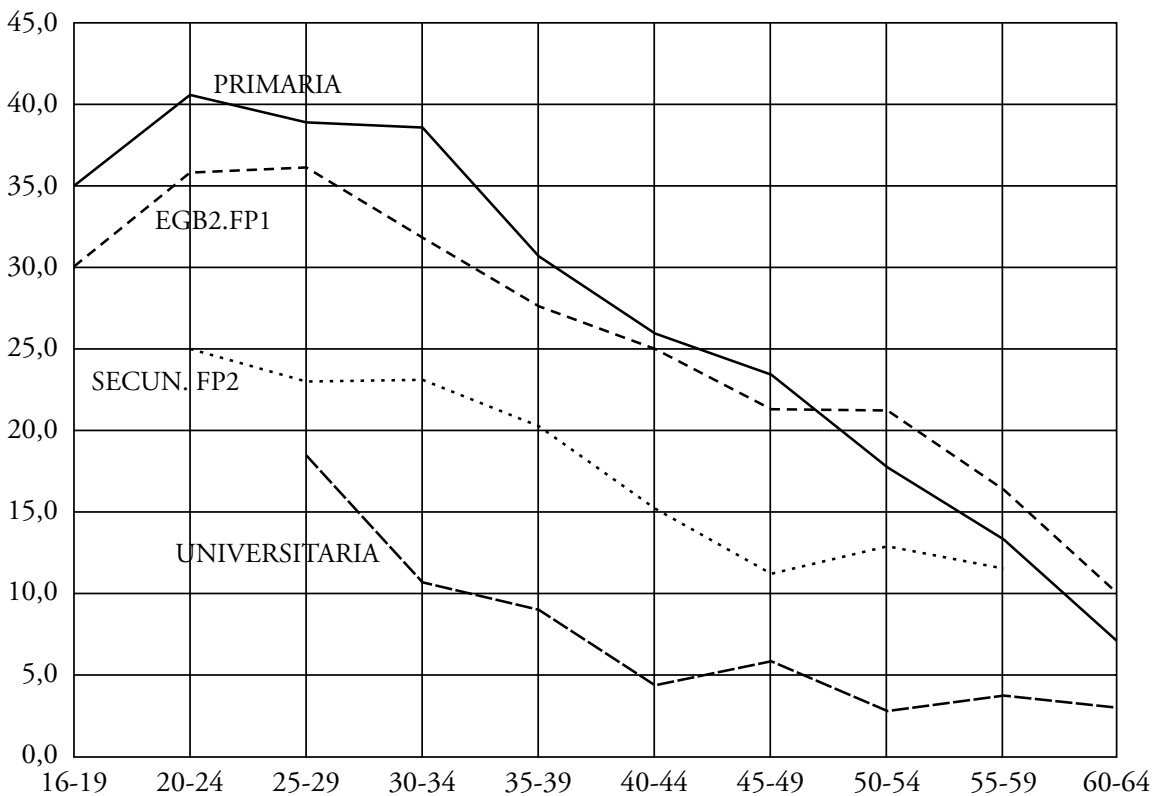

FUENTE: EPA IV/1994. Como base se considera la población activa que ha trabajado antes y que no cursa estudios.

Dado que la dificultad temporal para encontrar el primer empleo es prácticamente equivalente para todos los niveles de estudios y que el paro experto absoluto de las mujeres es también muy semejante (salvo para las universitarias), se puede deducir una cierta igualdad social de la resistencia con la que las mujeres presionan sobre el mercado de trabajo. La explicación de esta semejanza es que cuanto menor es el nivel formativo alcanzado se da una mayor dificultad relativa para encontrar trabajo, lo que conduce a la salida de la población activa en mayor proporción cuanto menor es el nivel de estudios. Así, aunque el paro convencional es mayor en las de menor nivel de estudios, éste se compensa con una menor participación, dando lugar a una evolución semejante de las trayectorias de paro absoluto para los distintos niveles de estudios.

Los altos niveles de paro con experiencia de los varones de 30-34 años de edad que no han superado la secundaria obligatoria dejan ver que el problema no es tanto de primera inserción como de mantenimiento trabajando (ya sea en el mismo puesto o en diferentes). Estas dificultades en la consolidación de 
la integración laboral dejan en evidencia que las edades a las que se prolongan incluyen una parte importante de la fase de formación de la familia y, en esa fase, el paro origina unos retrasos decisivos para el normal desarrollo del ciclo vital.

Por lo tanto, la dimensión más problemática reside en la escasez de trabajo para los trabajadores descualificados. La interpretación habitual de esta realidad es: si los trabajadores más cualificados consiguen más fácilmente la consolidación laboral que los no cualificados, formemos más a los parados y así, al ponerlos en las condiciones de cualificación de los que encuentran empleo, lo encontrarán ellos a su vez. Pero eso es proyectar sobre el sistema productivo la interpretación individual de las ventajas de la formación. En la competencia individual por un puesto de trabajo concreto, los más capacitados adelantarán en la cola de acceso a aquellos que sean previsiblemente menos productivos. Pero el proceso se limita a un cambio de orden de entrada. Los puestos que se ofertan tienen una estructura concreta que no varía de forma decisiva porque los candidatos estén más cualificados. Una sobreformación generalizada lo que conseguiría sería aumentar el nivel cultural medio de la población, pero no aumentar significativamente la cantidad total de puestos de trabajo disponibles. Si esto es así, la cuestión fundamental del paro hace referencia a la estructura de la calidad de los puestos de trabajo.

En un sistema productivo concreto el número de empleos de alta calidad es difícil de alterar a voluntad, dado que está asociado a la capacidad social para adaptar su sistema productivo a las mejores formas de producir que son accesibles en un momento dado. Estas mejores maneras incluyen la conjunción ajustada de la utilización del capital físico disponible con la capacidad organizativa y con la adecuación entre los conocimientos que incorpora la tecnología y su aplicación conseguida a través de la formación profesional de los trabajadores. Estos acoplamientos y ajustes entre los distintos subsistemas dificultan el cambio de la proporción de este tipo de puestos en un momento dado, tanto para la creación de nuevos puestos como para la destrucción de los existentes.

La aplicación de los conocimientos, entendidos como capital humano, tiene dos inercias sociales importantes derivadas de los plazos para su puesta en funcionamiento.

Por una parte, para aprovechar los efectos de formar de una manera innovadora se necesita diseñar la nueva formación, impartirla y poner a trabajar a los así formados de tal modo que se les permita aplicar sus conocimientos. Para poder incorporar eficientemente a los nuevos trabajadores se hace necesaria, frecuentemente, la sustitución de los que les supervisan. Esta sustitución es necesariamente lenta. Por ello la formación de los candidatos a trabajadores supone unos largos plazos, de tal modo que, a pesar de la importancia de las mejoras formativas, se puede dar por supuesto que no surtirán efectos inmediatos. Además, esta distancia temporal entre la oferta educativa y la demanda productiva da lugar a frecuentes desajustes entre los precios y las cantidades esperados y los salarios y la demanda finalmente obtenidos. 
Por otra parte, para innovar en la organización de la producción se necesita experimentar en organizaciones reales, y dada la complejidad y la variedad de situaciones productivas, sectores de actividad y mercados accesibles, esta innovación se deja en su mayor parte al sistema darwiniano de la prueba y el error por parte de las empresas y de sus direcciones. El funcionamiento correcto de esta selección natural conlleva la desaparición de las empresas ineficientes, o la sustitución de sus directivas en el caso de que su tamaño les permita sobrevivir a períodos lo suficientemente largos como para que quede demostrada su ineficiencia. Estos procesos de regeneración empresarial y directiva son más lentos que los formativos, y su inercia intrínseca se ve aumentada por las voluntades individuales de supervivencia institucionalizadas por los sistemas de propiedad y por los de regulación y control.

Parece claro que la alternativa consiste en formar a los que trabajan y en hacer trabajar a los que se forman. Esta es la línea de las políticas educativas (LOGSE) y de formación ocupacional (FORCEM) que se están poniendo en marcha actualmente en España. Esta tendencia es deseable pero difícil de aplicar, ya que la dinámica laboral concede pocos márgenes temporales para la adquisición de nuevos conocimientos. En cualquier caso, es la vía más rápida para incorporar eficientemente los adelantos específicos asociados a las tareas concretas. En este aspecto, las notables diferencias entre las formaciones básicas de las sucesivas generaciones de españoles hace más costosa (a veces casi imposible) la adaptación de los trabajadores mayores. A pesar de que da la sensación de que enseñar a los parados es una política más igualadora que hacerlo con los ocupados, el formar y acoplar productivamente a los ocupados a sus puestos concretos genera más estabilidad, ya que el aumento de productividad disminuye el riesgo de desaparición del puesto. Además, si se mantiene la opción por dificultar la creación de puestos de bajo nivel (que, como se verá, es la vigente en la España actual), es incluso más necesario elevar la eficiencia y cualificación concreta de los puestos existentes, ya que éste es el camino para incrementar la cantidad total de puestos. En todo caso, esta dinámica no resuelve la realización de las tareas de bajo nivel.

En España, la parte de la formación para el desempeño de las profesiones que se realiza en la universidad es mayor que en los países de su entorno, al tiempo que hay más plazas educativas para los estudios de ciclo largo. Esta peculiar configuración del sistema educativo es producto del control de su evolución por la oferta del propio sistema. Tanto la demanda de plazas por parte de los estudiantes como la demanda de egresados por parte de las empresas han tenido una muy escasa influencia en el desarrollo del sistema educativo. En particular, la denominada Autonomía Universitaria ha sido el escudo con el que la universidad se ha aislado de esas posibles influencias. El Consejo Social que se instituyó en la Ley de Reforma Universitaria para vincularla a la empresa fue prácticamente disuelto en sus funciones fundamentales por sentencias dictadas por altos tribunales formados en buena parte por catedráticos de universidad.

Actualmente, en España se está procediendo a la implantación de los nue- 
vos planes de estudios. El carácter problemático de estos planes, diseñados en gran parte por los profesores concretos que preveían impartirlos, ha dado lugar a un informe negativo del Consejo de Rectores que ha retrasado su implantación en las universidades que no la habían comenzado. En general, las críticas hacen referencia a la dispersión y al incremento de coste sin apreciable mejora de la calidad. Sin embargo, desde la perspectiva del mercado de trabajo se pueden plantear otros problemas. Uno de importancia es la reducida atención a las aplicaciones profesionales en algunas carreras, junto con el cierre por áreas de conocimiento de las licenciaturas, excluyendo frecuentemente una interdisciplinariedad que es demandada por el sistema productivo. Se diría que las universidades encomiendan las dimensiones aplicadas y la complementación de los conocimientos a los numerosos estudios de postgrado que proliferan en el espacio educativo español como vía para mejorar la posición de competencia de los licenciados. Este es otro elemento que prolonga el tiempo de dedicación a los estudios de los jóvenes.

La realización de prácticas laborales en la propia profesión, o de trabajos "de estudiantes», es muy escasa en la universidad española. La universidad permanece desconectada de la empresa en ambos sentidos.

Su clientela de más edad está mayoritariamente formada por funcionarios a quienes su limitada intensidad de trabajo les permite continuar estudios (o multiplicar sus títulos) como sistema de promoción en sus puestos administrativos. A ello colabora la escasa parte del coste de la plaza universitaria que paga el estudiante. El sistema de financiación de la universidad parece que sería manifiestamente mejorable. La respuesta empresarial a esta desconexión entre la universidad y el mercado de trabajo es una participación proporcionalmente reducida de los titulados universitarios en el sector privado. Para una gran mayoría de los universitarios, el Estado los forma y el Estado los contrata.

Respecto a la formación profesional, tanto reglada como ocupacional, el proceso de transformación es tan actual y de tal entidad que no parece accesible hacer una mínima evaluación de sus futuros efectos. Por ello se describen los grandes trazos de estos cambios.

El Programa Nacional de Formación Profesional (PNFP) elaborado por el Consejo General de Formación Profesional para el período 1993-1996 tiene como finalidad unificar y orientar la FP en una perspectiva laboral. La línea fundamental que se persigue con el PNFP es acercar y vertebrar la FP respecto a las necesidades del mercado de trabajo. En este programa la FP reglada queda a cargo del sistema educativo; la FP ocupacional para trabajadores desocupados se gestionará por el Instituto Nacional de Empleo (INEM), del Ministerio de Trabajo y Seguridad Social ${ }^{8}$, y la formación continua para trabajadores ocupados será gestionada por los agentes sociales a través de la Fundación para la Formación Continua (FORCEM).

${ }^{8}$ Y por las Comunidades Autónomas con competencias en la materia: Andalucía, Cataluña, Galicia y Comunidad Valenciana. 
Esta Fundación es producto del Acuerdo Nacional de Formación Continua (ANFC), que fue suscrito por las organizaciones empresariales CEOE y CEPYME y las centrales sindicales CC.OO., UGT y CIG y entró en vigor el 1 de enero de 1993. También en 1993 comenzó a aplicarse el Acuerdo Tripartito firmado en 1992 entre los interlocutores sociales y el Gobierno, por el que éste se compromete a financiar el nuevo sistema de formación continua. En el acuerdo tripartito se estipula que una fracción del porcentaje (que es del 0,7 por 100) sobre las cotizaciones recaudadas que se venía dedicando a la formación de los desempleados se dedicará de ahora en adelante a la formación de trabajadores asalariados.

Respecto a la FP reglada se ha llevado a cabo una reforma completa con la introducción de una FP3 de carácter superior. Aunque esta reforma parte de la Ley Orgánica 1/1990, de 4 de octubre, de Ordenación General del Sistema Educativo (LOGSE), la implantación completa de la nueva FP no se producirá hasta el curso 1998-99, y la extinción de la actual culminará en el año 2001. Por ello los efectos de la deficiente FP1 todavía seguirán siendo apreciables. En particular, la alta tasa de paro de estos titulados. Una de las innovaciones fundamentales de esta ley es la obligatoriedad de realizar prácticas en las empresas. Estas prácticas no tienen relación alguna con los contratos de prácticas. El éxito de su implantación dependerá en gran medida de la reglamentación concreta de las condiciones en las que se realizarán dentro de las empresas y de la forma en la que se consigan concertar los intereses de los estudiantes con los de las empresas. Dada la obligatoriedad para los estudiantes, parece que sería indispensable incentivar a las empresas para conseguir una amplia aceptación de estas prácticas?.

Uno de los instrumentos iniciales para la vertebración del PNFP consiste en la creación de un sistema nacional de cualificaciones profesionales en el que la formación adquirida en los subsistemas sea convalidable, actualizando el catálogo de títulos de la FP reglada, y el repertorio de certificaciones profesionales de la FP ocupacional como camino hacia la transparencia de las cualificaciones en el ámbito de la Unión Europea (CES, 1994, 93).

La Fundación para la Formación Continua (FORCEM) dispondrá el primer año del 0,1 por 100 de las cotizaciones (equivalente a 18.000 millones en 1993, que, como se recordará, se extraía del 0,7 por 100 dedicado a la formación), creciendo hasta el 0,3 por 100 en 1996. Esto se obtiene de sacar del Plan FIP la formación de los ocupados que se denominaba formación continua. El FORCEM ha gastado, en 1993, 11.000 millones de pesetas y, en 1994, 39.000 millones, de los que 13.900 van a planes de empresa, 19.100 a planes agrupados y 5.800 a planes intersectoriales.

Mientras que el Plan FIP ha dado formación a alrededor de 200.000 para-

9 Las dificultades para concertar las prácticas de los alumnos de formación profesional parten en su mayoría de la negativa de los empresarios a acoger a tales alumnos. 
dos cada uno de los últimos tres años ${ }^{10}$, los planes del FORCEM han afectado en 1994 a 1,295 millones de trabajadores ocupados, de los que más de la mitad corresponden a trabajadores de grandes empresas. La política del FORCEM supone una importante transferencia de recursos que antes se destinaban a la formación de los desempleados.

\section{LA COMPOSICION DEL PARO Y LA CALIDAD DE LOS PUESTOS}

En la España del último decenio se han puesto en práctica diferentes políticas para fomentar el empleo juvenil. De entre ellas cabe destacar la eficacia distribuidora de los llamados contratos temporales de fomento del empleo. Uno de sus efectos ha sido disminuir la dificultad de logro del primer empleo. Ya hemos visto que, con respecto a su participación laboral, la situación de los jóvenes no ha venido siendo sensiblemente peor que la de sus mayores, salvo durante la crisis de 1976-1985. Para valorar el bloqueo que se produjo entonces se puede observar la relación entre las cantidades de buscadores de primer empleo y las de parados que han trabajado antes (paro experto). Esta relación nos proporciona un índice que es una combinación del cierre del mercado y de la rotación de los trabajadores. Su crecimiento indica un bloqueo de la incorporación laboral de los jóvenes, mientras que su disminución puede deberse a una apertura (por disminución del numerador: el paro de primer empleo) o una mayor rotación (por aumento del denominador: el paro con experiencia). En el gráfico 7 se observa la evolución del nivel de bloqueo del acceso al primer trabajo.

Durante la primera parte de la crisis (entre 1976 y 1982), mientras crecía el paro general, la proporción de buscadores de primer empleo respecto a los que habían trabajado antes pasaba del 50 al 70 por 100 , para estabilizarse alrededor de ese nivel hasta 1986, poniendo en evidencia la grave dificultad para acceder al primer empleo por parte de los jóvenes.

La expansión económica del quinquenio 1985-90, junto con la progresiva generalización, a partir de 1986, de estos contratos «temporales de fomento del empleo» y de los de formación y prácticas (también temporales y bonificados), consiguió desatascar la entrada a la ocupación. A lo largo de esta fase de recuperación del empleo el paro juvenil total disminuyó en términos absolutos y relativos y en 1990 por cada 100 parados expertos había 40 que buscaban el primer empleo. Pudiera pensarse que esta mejora de la incorporación era un efecto de la coyuntura laboral favorable; sin embargo, hasta finales de 1993 siguió mejorando la eficiencia relativa de los buscadores del primer empleo, a

${ }^{10}$ En 1991: 196.000; en 1992: 206.000, y en 1993: 174.000. El porcentaje de estos formados que han encontrado empleo en el año siguiente al de realizar estos estudios ha sido del 30 por 100 en 1991, 37 por 100 en 1992 y 32 por 100 en 1993. Estos porcentajes no son muy alentadores, ya que se asemejan en gran medida al 25 por 100 que logran los que no los han cursado. 


\section{GRAFICO 7}

Composición del paro entre 1977 y 1995

(parados en millones y buscadores del primer empleo por cada cien parados expertos)

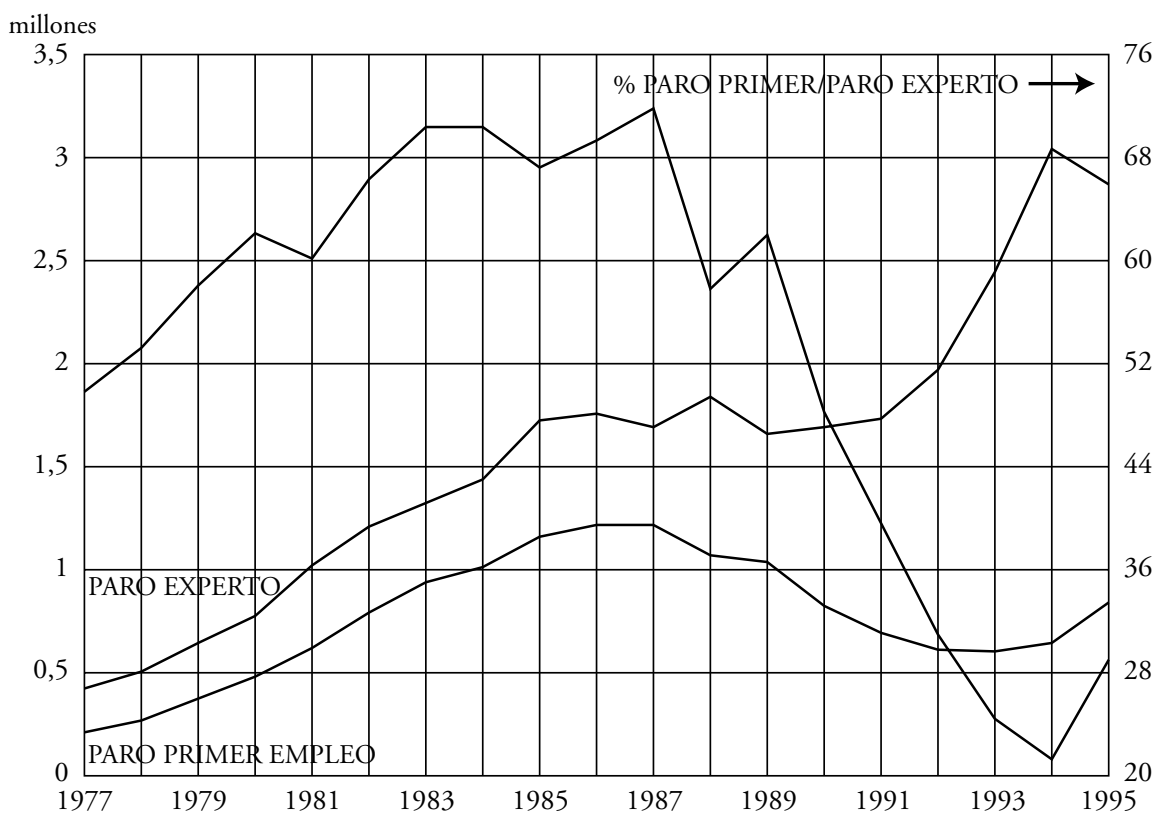

FUENTE: EPA, cuartos trimestres del año anterior.

pesar de que se produjo en estos tres años la más grave caída conocida del empleo. Se puede entender que esta parte de la disminución del índice, que alcanzó el 23 por 100 en el segundo trimestre de 1993, fue debida al incremento del denominador (los parados expertos), pero, incluso en términos absolutos, la cantidad de buscadores del primer empleo siguió descendiendo, aunque levemente, entre 1990 y 1993.

En 1992 se restringieron las condiciones de estos contratos (el límite mínimo de los de fomento del empleo pasó de seis meses a doce meses y se quitaron las bonificaciones a los de formación y prácticas) y en 1994 se han eliminado los de fomento y se han sustituido los de formación. El II/1994 el índice subió a 26 y el IV/1994 a 29. Es posible que el incremento del índice esté asociado a estos cambios normativos.

$\mathrm{El}$ argumento fundamental de este trabajo consiste en la necesidad de elección entre desempleo y desigualdad laboral. En realidad, esta alternativa es más empírica que decisional y se puede formular como la opción prácticamente 
ineludible entre dos clases de desigualdad: la que se deriva de las diferencias de cualificación, condiciones de trabajo y/o de salarios entre las distintas ocupaciones o la que media entre los que están ocupados y los que no lo están.

La opción entre un mayor o menor crecimiento del empleo para un crecimiento dado pasa por el nivel de desigualdad en los empleos que se admita como tolerable. Cuanto mayor es la igualdad en la estructura ocupacional, menor es la cantidad de empleos para un crecimiento dado. En ello se encuentra buena parte de la explicación de la especial relación entre las evoluciones de la productividad y del empleo en España.

En España, si se analizan los períodos de recesión económica, en los que es escaso el crecimiento del PIB, se observa, en el gráfico 8, que la productividad

\section{GRAFICO 8}

Variación anual del empleo, la productividad y el PIB entre 1978 y 1994

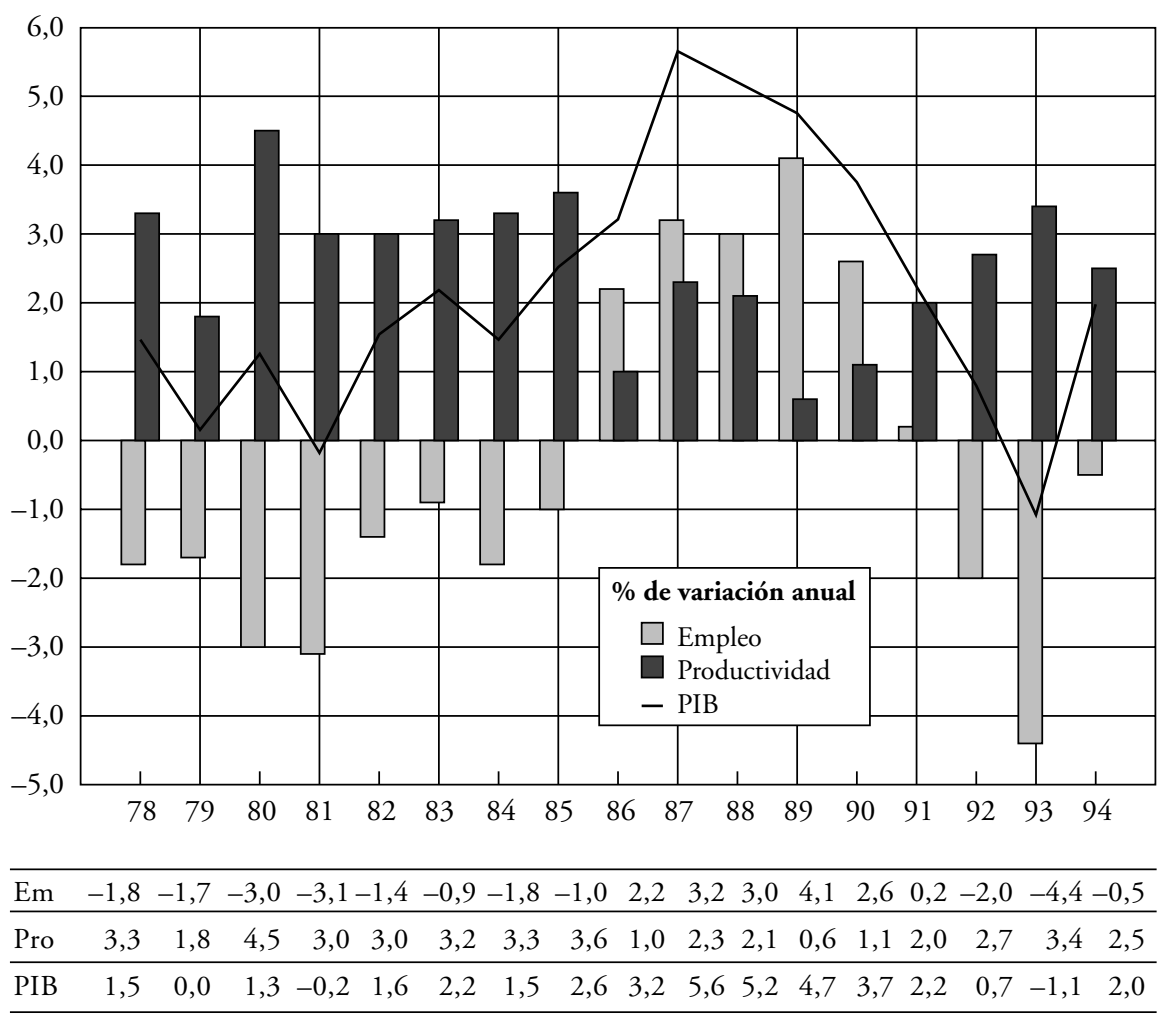

Fuente: Series de la D. G. de Previsión y Coyuntura del Ministerio de Economía y Hacienda. 
por trabajador ocupado sube de forma importante. Muy al contrario, este crecimiento disminuye apreciablemente hasta casi estancarse en las fases de expansión. Los manuales de economía plantean una evolución que es la contraria a la indicada. Un elemento importante a considerar y que forma parte de estos procesos consiste en la elevada pérdida de puestos de trabajo que acompaña a las recesiones, y la notable creación de empleos que se ha producido durante la recuperación del empleo de 1985-1990.

La explicación más frecuente del aumento de la productividad es la que lo atribuye al progreso técnico y organizativo aplicado a la producción. Otra explicación utilizada a menudo considera que la productividad de los que se mantienen ocupados permanece prácticamente constante y la subida global se debe a que los que son despedidos tenían una productividad sensiblemente inferior a la media. Este tipo de aumento medio es sólo aparente. Los incrementos de productividad reales serían los derivados de una mayor eficiencia de los ya ocupados como consecuencia del progreso, y los aparentes serían consecuencia de las diferencias de productividad entre los que conservan su empleo y los que lo pierden como efecto de la reconversión de la estructura productiva.

Otra parte importante del crecimiento de la productividad se debe a las nuevas contrataciones, que tienen una productividad sensiblemente superior a la media. Estas serán tantas como sea capaz de generar el sistema social (sistema reproductivo, educativo, productivo y mecanismos de asignación que los relacionan). Por ello es de esperar una mejora de la productividad aunque los ocupados no la incrementen (que es de suponer que lo harán, aunque a un ritmo medio lento).

Los trabajos de muy alta productividad relativa podrán disponer de buenos salarios y de condiciones de trabajo que, salvo en casos específicos por riesgo, etc., serán también superiores a la media. El sistema productivo no se puede permitir desperdiciar ningún puesto de trabajo que podríamos denominar «de calidad». De los trabajos de los que puede prescindir la sociedad es de aquellos de baja productividad en los que los salarios no pueden ser altos porque el producto obtenido es escaso o poco apreciado.

En las épocas de alto crecimiento la circulación de recursos es mayor y aumenta la demanda general de los consumidores, con lo que se amplía el margen de productos y servicios vendibles, siempre que la escala entre el excedente disponible se ajuste al precio de esos bienes añadidos. Si en esas épocas se facilita la oferta a precios bajos, el crecimiento del empleo está servido.

Cuando llega la recesión es necesario desprenderse de los elementos menos productivos, ya que si se restringen los recursos es lógico que se prescinda de aquello que menos aporta. Este componente es más radical en el caso de los puestos de trabajo que son afectados directamente por los cambios introducidos en el sistema productivo y que combinan la escasa producción (o la producción de bienes o servicios cuya demanda haya caído) con costes salariales altos. En general, a la desaparición de este tipo de puestos se le puede denominar reconversión. Si cuando arrecia la recesión se dificulta el ajuste del empleo vía costes, éste se efectúa vía cantidades. Cuando entre 1990 y 1991 estaban 
disminuyendo suavemente las contrataciones de jóvenes con contratos flexibles o bonificados se respondió eliminando esas bonificaciones, y cuando las expectativas de futuro se oscurecían rápidamente se aumentó el tiempo mínimo de contratación temporal. El resultado fue una disminución considerable del total de contratos y, en particular, la caída en picado de las contrataciones específicas para los jóvenes. A esta caída se puede añadir una cierta sensación de traición por parte de los empleadores, que ven que cuando la situación política se le pone mal al gobierno, éste rompe las reglas del juego aumentando las dificultades y los costes a la contratación.

Curiosamente, la respuesta pública no hizo referencia a los efectos de incremento del paro a los que estas modificaciones legales darían lugar, y al hecho de que, con toda probabilidad, serían los puestos de trabajo más débiles los que desaparecerían, sino que se entendió que la supresión de las bonificaciones y la rigidificación de los contratos eran una carga mayor para los empleadores y, por ello, una justa compensación a la dureza de las reducciones en la cobertura del desempleo. Nadie pareció prever que los trabajadores terminarían perjudicados por los dos lados de la balanza y que el ahorro que produciría la disminución de las prestaciones del desempleo se podría ver pronto superado por el incremento de la cantidad de parados. El saldo final consistió en mayor destrucción de empresas (sobre todo las menos productivas que no podían mantenerse sin las bonificaciones), mayor paro y mayor gasto social total. Las épocas de recesión no son las mejores para aumentar las restricciones a la movilidad y el coste global del trabajo.

En la reforma laboral actual se han cambiado los contratos de formación (que en algunos casos de formación tenían casi únicamente el nombre) por los contratos de aprendizaje. El que sea posible la contratación durante tres años a salarios inferiores al mínimo interprofesional, junto con una protección social incompleta, les ha ganado el calificativo de contratos basura. Sin embargo, a efectos de la posible amplitud de su implantación, su regulación es más restrictiva que los anteriores, no sólo por lo relativamente reducido del colectivo al que van dirigidos (705 mil parados entre 16 y 24 años de edad que no estén estudiando y no hayan alcanzado ningún título de formación para la ocupación) como, sobre todo, porque la regulación de la proporción de aprendices por empresa hará más limitada su utilización dado que no se podrán formar empresas compuestas por puestos de aprendices. Tampoco será posible contratar a un aprendiz en una ocupación en la que ya lo haya sido anteriormente. De los 16 a los 24 años hay nueve años y en muchos de los puestos (la mayor parte de los peones, los repartidores... en los que se pueden contratar a los jóvenes descualificados) no puede obtenerse prácticamente ninguna formación, con lo que para todos ellos se está procediendo a una marca que les impida seguir trabajando en lo suyo ${ }^{11}$.

${ }^{11}$ Entendido como espacio social. Los sectores de actividad, además de ámbitos de producción de ciertos bienes o servicios, configuran mundos sociales específicos. 
No se pretende defender que ese tipo de empresas y de puestos sean deseables, sino más bien afirmar que, precisamente porque son relativamente prescindibles, si se dificulta o impide su existencia, eso no produce más empleos de calidad, simplemente disminuye la cantidad total de empleos. La cuestión es si la sociedad se resigna a tener una proporción apreciable de puestos de trabajo descualificados (en los que no es necesario ni posible el aprendizaje) de bajos salarios y de cierta rotación o si se resigna al paro.

La otra opción al paro es el empleo autónomo que sirve de refugio (frecuentemente familiar) en las épocas en las que se dificulta especialmente el acceso al mercado de trabajo. A pesar de la relativa apreciación que el trabajo por cuenta propia tiene entre los analistas, en España sus características generales le sitúan frecuentemente en peores condiciones que el correspondiente asalariado. Jornadas de trabajo mayores, niveles de cualificación más bajos, menor cobertura de la Seguridad Social, ausencia de planes de formación públicos... El crecimiento contracíclico de esta forma de ocupación no obedece tan sólo a estrategias empresariales de evitación de las cotizaciones sociales, sino que debe ser interpretado como una forma de expulsión del mercado de trabajo propiamente dicho ${ }^{12}$.

Si se estudia la evolución de la estructura ocupacional española clasificando las ocupaciones por la media de estudios de quienes las ocupan en un momento dado (fijando así un índice aproximado de los probables requerimientos de formación de esos puestos ${ }^{13}$ ), se observa que la proporción de puestos de los niveles más altos ha venido creciendo durante los dos últimos decenios de manera prácticamente continua. Sin embargo, los puestos de trabajo definidos como de bajo nivel (por la escasa formación de quienes los ocupaban en un momento fijo) se ven afectados por la conjunción de las políticas de empleo con la fase de ciclo económico. Como se puede apreciar en el gráfico $9^{14}$, cuando hay recesión los puestos de menor nivel desaparecen en mayor proporción que los de alto nivel, mientras que en las expansiones mantienen en mayor medida su presencia en la estructura ocupacional.

${ }^{12}$ Esta interpretación exige un análisis detallado de la evolución de las diferentes ocupaciones y sectores en los que se da una importante proporción del trabajo por cuenta propia, ya que las diferencias por niveles de cualificación (de los puestos, no de los trabajadores) obligan a importantes matizaciones.

${ }^{13}$ Este índice sirve para ordenar las diferentes ocupaciones de una manera fija a lo largo del tiempo. Esta fijación sirve para evitar la influencia del continuo incremento de nivel formativo de los trabajadores. Los plazos en los que se puede mantener fija esta clasificación son necesariamente limitados y se deben asociar a los cambios organizativos del sistema productivo que pueden ser detectados por la transformación de la matriz ocupaciones por sectores de actividad, que es la que define la composición del empleo para cada rama de la producción. Aunque esta investigación está en sus inicios, parece que podría proveer un sistema de medida de la evolución de la desigualdad en la estructura ocupacional relativamente independiente de los salarios y del crecimiento general de la formación de los ocupantes. Este método sería, obviamente, más eficaz si se pudiesen definir las ocupaciones por las tareas que efectivamente se realizan en ellas y no por los nombres de una clasificación que, a menudo, no quieren decir lo mismo para las diferentes personas y los diferentes lugares.

${ }_{14}$ Todos los datos corresponden al segundo trimestre. 


\section{GRAFICO 9}

Asalariados: variación anual de los tamaños de los grupos de ocupaciones construidos ordenando en 1987 las medias de cualificación de los puestos

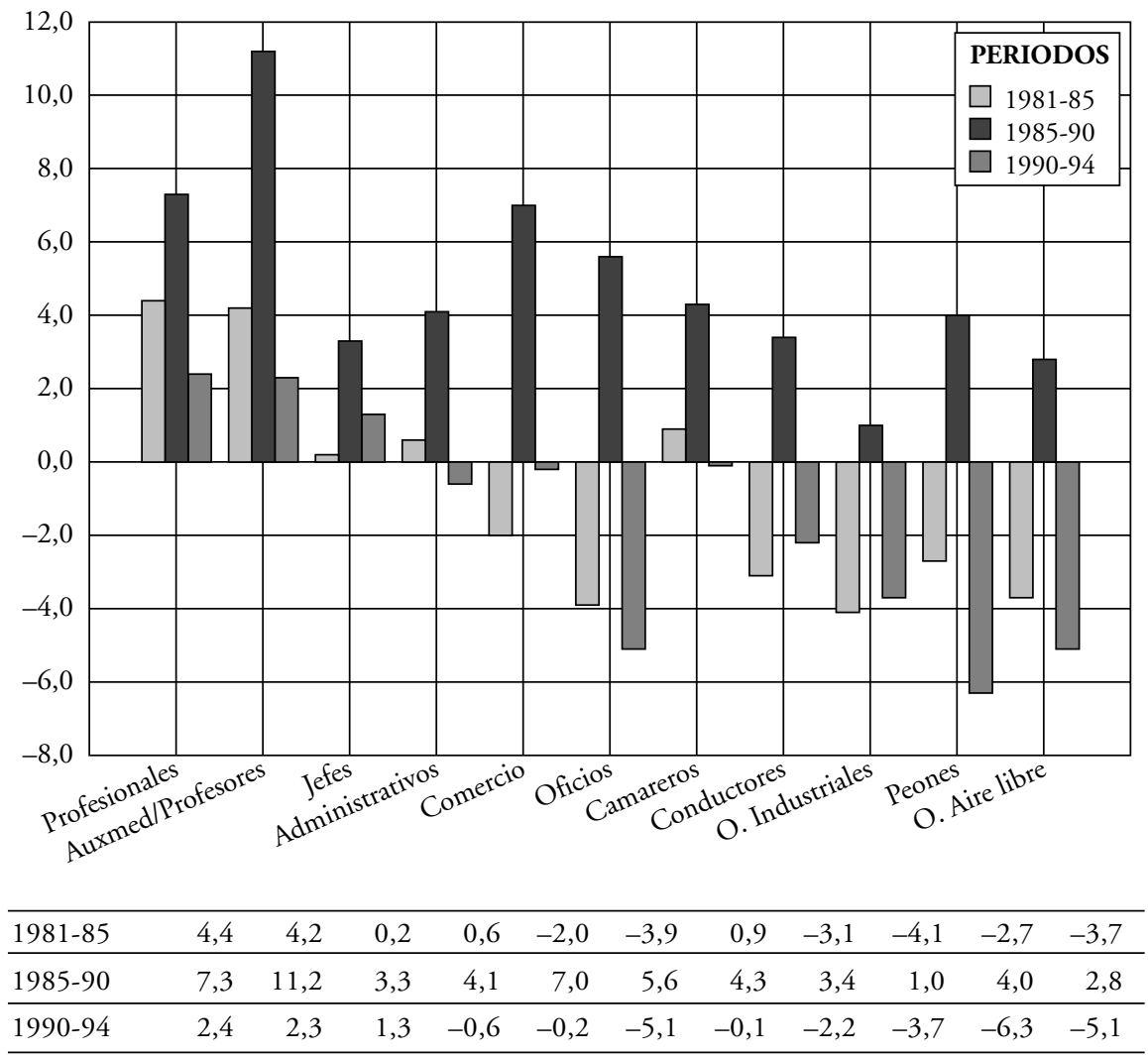

FUENTE: EPA, II trimestre.

Si se divide a los trabajadores manuales no agrarios en cualificados y no cualificados mediante una metodología semejante para España e Inglaterra ${ }^{15}$, no deja de resultar sorprendente que en España haya 54 obreros descualificados por cada cien cualificados, mientras que en Inglaterra, que es considerada

15 Juan Jesús GONZÁLEZ (1995), Desigualdad: factores, tendencias y actitudes ante el problema (mimeo), como producto de la investigación internacional sobre «Estructura, Conciencia y Biografía de Clase». Como una de las alternativas analíticas, y siguiendo a J. Goldthorpe, González afirma que «lo que caracteriza el caso español es una menor polarización de estructura clasista, pero conviene ser cauteloso en esta afirmación». El motivo de la necesidad de cautela es, como sería de esperar, el ambivalente carácter del trabajo por cuenta propia. 
el paradigma de la modernidad en materia de estratificación, hay 94 descualificados por cada cien cualificados. Parece contradictorio que un país más desarrollado tenga una proporción de obreros descualificados tan notablemente superior a la que presenta un país como España. Se podría pensar que, aparte de la importante proporción de trabajo descualificado que se refugia (fuera del mercado asalariado) en el trabajo autónomo, hay también un probable contingente de trabajo no cualificado que no encuentra acomodo dentro de la estructura institucional del trabajo asalariado.

Por otra parte, no es seguro que las empresas que nacen al abrigo de condiciones de contratación bonificadas no puedan desarrollar evoluciones de servicios o productos que les permitan trabajar más adelante en mejores condiciones. En esta misma línea, y en el plano individual, más importante que la estabilidad en un mismo empleo es la estabilidad en el empleo. Es decir, que lo importante es la prontitud con la que se encuentra otro empleo si se pierde el actual. En Estados Unidos la gran cantidad de puestos de baja cualificación hace que la duración del paro en estos niveles sea muy reducida, al contrario de Europa (y España), en la que si se pierde el empleo es difícil encontrar otro porque el contingente de buscadores es claramente superior que el de puestos. La demostración de esta causación se dio en España durante la recuperación (1985-90). Al aumentar la cantidad de puestos de menor calidad (baja cualificación y menor estabilidad contractual) disminuyó de una forma contundente el paro de larga duración, que los analistas consideraban enquistado.

Otra cuestión decisiva para la interpretación de los efectos sociales de la existencia de puestos de baja calidad es la relacionada con la movilidad biográfica a través de ellos ${ }^{16}$. Es diferente que sus ocupantes no puedan progresar de tal modo que se cronifique su mala situación, a que sea fácil ir cambiando a puestos mejores y así hacer esos trabajos de bajo nivel durante una fase acotada de la biografía laboral. Desde este punto de vista, parece más adaptativo al sistema productivo estar trabajando que permanecer parado.

Finalmente, la traslación de la desigualdad de salarios y de condiciones de trabajo desde el ámbito propio del mercado hasta el ámbito de la familia (ya sea a través del trabajo por cuenta propia ${ }^{17} \mathrm{o}$ en la dependencia a la que da lugar el paro, sobre todo el de primer empleo) hace pensar que la desigualdad de condición económica debería ser considerada desde una perspectiva familiar y no individual. Por mucho que el posible aumento de la proporción de puestos de bajo nivel aumentara la desigualdad individualmente considerada, es altamente probable que disminuyese la desigualdad de las unidades familiares, ya que permitiría la multiplicación de rentas en los hogares constituidos por

16 Gosta Esping Andersen (1993), Empleo postindustrial y estratificación, en el vol. V, Estructura social y movilidad, Madrid, pp. 35-45. Publicado por la Fundación Argentaria como resultado del I Simposio sobre Igualdad y Distribución de la Renta y la Riqueza.

${ }_{17}$ Que por sus características empíricas puede ser denominado modo de producción familiar (Garrido, 1991, 193-198). 
individuos de baja cualificación, que son los que soportan mayores índices de paro junto con una mayor duración de éste ${ }^{18}$.

\section{POSIBLES LINEAS DE ACTUACION}

\section{Disminución del coste indirecto de los trabajos descualificados}

Una de las cuestiones fundamentales de la importancia del monto total de los salarios es su carácter que podríamos denominar cuántico, o en "paquetes». La cantidad de dinero que un individuo recibe por su participación en la producción es indivisible de lo que necesita para vivir. Cuando se forma una familia se disminuyen los costes de escala, pero la propia constitución familiar obliga a fuertes inversiones iniciales. Un camino para que sea posible vivir con salarios bajos consiste en que los costes asociados a esos salarios los descuente el Estado de sus ingresos potenciales.

El problema de la integración y la consolidación de los jóvenes en el trabajo aparece asociado en gran medida a la disminución de los puestos descualificados, que dificulta la incorporación de los jóvenes con menores niveles de cualificación ${ }^{19}$.

Una vía para evitarlo podría consistir en bajar el coste del trabajo de las ocupaciones de más bajo nivel sin afectar al salario percibido por el trabajador, e incluso elevándolo mediante recursos indirectos como pueden ser la vivienda y otros servicios. Su objetivo sería aumentar el número de puestos de trabajo personal, social e institucionalmente viables.

Dentro de la bajada de costes figuran los impuestos directos y la seguridad social de los empleadores. La bonificación de las cotizaciones de la Seguridad Social es preferible a la subvención puntual, ya que permanece de forma continua la ventaja de mantener contratado al trabajador. Para aumentar la estabilidad se puede hacer creciente esa bonificación dentro de límites concretos de edad. Además, las bonificaciones no comportan más compromisos que la diferencia de precio del trabajador respecto al posible sustituto. Los compromisos asociados a las subvenciones en el momento de convertir el contrato en indefinido disminuyen la capacidad de adaptación a las condiciones del mercado y a la posibilidad de conseguir otros trabajadores mejor preparados. En este sentido, la eliminación de la bonificación a los contratos de prácticas no está acorde con la eficacia que tuvieron en los años en los que estuvieron en vigor.

18 Aunque la homogamia entre los profesionales tiene el efecto contrario, ya que hace que el trabajo de la mujer contribuya a la igualdad (en función del sexo) entre individuos pero entre los hogares produce un efecto de aumento de la desigualdad, ya que concentra dos sueldos altos en la misma pareja (González, 1995, 11).

19 No los descualificados, sino los últimos de la fila de la cualificación. 


\section{Los márgenes de edad}

Con respecto a los márgenes de edad a los que es recomendable prolongar la políticas de integración, éstos dependen del tipo de actuación, pero debe estar acorde con los diferentes calendarios de ingreso en la ocupación. Para las políticas de consolidación de la integración cabe ${ }^{20}$ prolongarlos hasta los 30 años - la integración laboral máxima de los varones (y de las mujeres solteras) se «cumple» a los 33 años-. En realidad, como se ha visto en la evolución por niveles de estudios del paro de primer empleo, las integraciones laborales se segregan por edad (como es lógico) en función del nivel de estudios alcanzado. Al tiempo, y en asociación con el grado de cualificación logrado, se pueden detectar también calendarios diferentes para la integración en el sector privado, el sector público y el trabajo por cuenta propia.

Como aproximación a la evolución general de los calendarios de los jóvenes, comparando la situación de 1976 con la de 1994 en cuanto a la inserción laboral, la primera nupcialidad y el acceso a la vivienda, los resultados son que, desde 1976, la edad del acceso al empleo se ha retrasado seis años, la del matrimonio tres años y el logro de la vivienda se realiza con dos años más de edad que en $1994^{21}$.

Dado que la notable disminución del trabajo de ayuda familiar ha cambiado una de las componentes de esta evolución, se puede simplificar diciendo que entre los 16 y los 20 años se produce la primera integración descualificada en el sector privado, que se sigue de otra de nivel medio entre los 19 y los 23 también como asalariados privados. A los 23 y hasta los 28 se inicia una primera fase de integración de los profesionales en el sector público. Entre los 29 y los 34 se consolida la integración en el sector público, mientras que el trabajo por cuenta propia, que desde las edades más tempranas había estado compuesto de ayudas familiares y trabajadores autónomos, crece en estas edades el componente de autónomos como resultado del establecimiento de los negocios familiares (comercio, agricultura, hostelería, restauración, etc.).

Esto hace ver que respecto a los asalariados se pueden distinguir al menos dos fases, una que va de los 16 a los 22 años en el sector privado con cualificaciones bajas y medias, y otra de los 23 a los 31 años en el sector público con altas cualificaciones.

20 Esta línea ya se ha seguido con las subvenciones, ya que en la Ley 22/92 y en el RD 3/93 se amplía a los 29 años el margen de edad de aplicación del contrato para menores de 26 años de edad del RD 799/85, que estuvo en vigor desde el 25-5-85 hasta el 25-1-88. Esta subvención de 400.000 pesetas por cada contrato indefinido tiene condiciones distintas para dos grupos diferentes de edad: para los menores de 25 años tienen que llevar al menos un año inscritos como desempleados en el registro del INEM; para los que tienen entre 25 y 29 años afecta a aquellos que no hayan trabajado con anterioridad por un tiempo superior a tres meses.

${ }^{21}$ Luis Garrido Medina y Miguel ReQuena y Díez DE ReVEnGa (1995), «El acceso de los jóvenes a la vivienda y al trabajo», Revista Asturiana de Economía (RAE), Oviedo, pp. 27-55. 


\section{La vivienda como salario social en especie}

Dado el decisivo peso del coste de la vivienda en los gastos de los españoles, un camino de posibilitar la existencia de bajos salarios sería facilitando el acceso a la vivienda. No tanto por la vía de la construcción como de la política de suelo urbanizado, entendido éste como una política de infraestructura básica. El alquiler parece en principio una fórmula más apropiada que la compra, pero eso es una cuestión nimia en comparación con la disminución de precios que supondría la concesión de suelo público urbanizado en un país que está prácticamente desierto, a excepción de Madrid y la costa, y en el que la vivienda resulta inaccesible para la casi totalidad de los jóvenes.

El proyecto $^{22}$ de eliminar las desgravaciones por compra de vivienda para los salarios mayores de 250.000 pesetas mensuales o para los pisos de más de 20 millones de pesetas tiene el inconveniente de que, además de la reducción de ayuda que supone, utiliza las desgravaciones que son indiferentes para los salarios más bajos. Trasladar el ahorro público a la desgravación de los alquileres choca con el mismo problema, ya que los bajos niveles de ingresos en las ocupaciones a las que se ha hecho referencia no permiten que las desgravaciones sean significativas. En todo caso, para estos trabajadores el impuesto sobre la renta debiese ser tendente a cero. El pago de impuestos indirectos es una carga fiscal suficiente para quien emplea la mayor parte de sus ingresos en bienes de primera necesidad. La desproporcionada importancia de los gastos de vivienda para los jóvenes es uno de los campos fundamentales de intervención para que los salarios bajos no sean un camino cierto de exclusión social. Una alternativa sería la subvención directa del alquiler, pero las políticas de subvención directa generan más fácilmente mercados segmentados.

Un efecto añadido de la promoción general de la vivienda sería el incremento de actividad económica que acompaña al aumento de construcción. Desde el punto de vista político, resulta sorprendente que se considere ineludible la obra pública gratuita (para los usuarios) cuando se dedica a transporte o a producción y que se escatime de tal manera cuando tiende a satisfacer una necesidad tan básica como es la vivienda. En general, hay que conseguir una política de vivienda que impida que sean factores como el precio del suelo los que cortocircuiten la inserción social de los jóvenes al tiempo que presionan al alza a los salarios.

\section{Los recursos y los incentivos}

Los incrementos de gasto a los que darían lugar estas políticas tendrían que proceder en buena parte de una reducción de las prestaciones por desempleo.

22 Que fue lanzado como globo sonda por la Secretaría de Estado de Vivienda y Medio Ambiente durante las últimas semanas y retirado ante la generalizada reacción adversa en los medios de comunicación. 
Para esta reducción un camino podría ser el considerar la situación familiar como referencia en la adquisición del derecho a la prestación. El gasto total en protección por desempleo en España fue en 1993 superior a los 2.119.000 millones de pesetas, casi el doble en términos reales del correspondiente a 1985 (CES, 1994, 61).

Por otra parte, según el Libro Blanco de Delors: un incremento de los puestos de baja cualificación con reducción de los niveles inferiores de rentas sólo sería compatible con una reducción similar de los subsidios de desempleo y de la cobertura de los regimenes de seguridad social, si no se quiere desincentivar la oferta de mano de obra y generar un mayor desequilibrio presupuestario.

Las medidas de bonificación (de cargas fiscales y de la seguridad social) de los salarios deben ser estudiadas de modo que la gradación no genere zonas de desigualdad intermedias. Estas zonas de nadie, «ni tan pobre como para tener apoyo, ni tan rico como para apoyarme a mi mismo", son especialmente perjudiciales por el efecto de desmotivación que producen. La gradación es también necesaria para evitar los efectos frontera. Si, por ejemplo, se articulan las ayudas con un único límite, la respuesta social se acumula en las zonas próximas a ese corte y a partir de él. Otro de los efectos perversos a evitar es que el resultado final de las ayudas haga más atractivas las posiciones de bajo nivel que las de nivel medio. La vigilancia de la estructura de incentivos es una de las cuestiones clave para conseguir el equilibrio social. Hay que eliminar la desigualdad que invalida, pero mantener la necesaria como para movilizar a los individuos hacia las posiciones y los comportamientos que son públicamente más eficientes.

Deben incrementarse los incentivos a las empresas para la realización de prácticas durante los estudios. Los estudiantes son entendidos por la empresa (y en muchos casos parece inevitable que sea así de hecho) como elementos inconvenientes para el buen funcionamiento. Sobre este supuesto es necesario que desde la perspectiva empresarial se produzca una clara ganancia que fomente su participación en la formación en alternancia que ahora se propone. Otro elemento clave para esta aceptación empresarial pasa por otorgar autoridad empírica a la empresa en el control del comportamiento del alumno. La cuestión de la autoridad afecta en general a la situación de las relaciones laborales en España.

Los contratos de aprendizaje son positivos para los puestos susceptibles de convertirse en cualificados. Pero ¿qué pasa con los puestos no cualificados de la sociedad?, ¿es que se supone que van a desaparecer completamente? Los datos con los que se cuenta sobre requerimientos de cualificación de los puestos nos hacen ver que hay una mayoría de puestos cuyas tareas no requieren prácticamente cualificación.

\section{El empleo público}

Respecto a la política de empleo público se plantean dos cuestiones diferentes. Por una parte, su comportamiento contracíclico ha sido impedido 
durante la última crisis por el desaforado aumento del déficit público. Esto ha llevado a la congelación durante dos años de los salarios de los funcionarios e incluso al descenso del contingente de asalariados públicos durante la fase más dura de la crisis. Parece que el condicionamiento económico está controlando directamente la improcedencia actual de esa política.

Por otra parte y para fases del ciclo más propicias, hay que distinguir claramente entre la administración que gestiona, regula y dirige (administra) el país y la que produce servicios que los ciudadanos consumen poco menos que directamente (como, por ejemplo, la sanidad o la educación). Es probable que la segunda pueda crecer para mejorar la cobertura de esos servicios, ya que el tratamiento de personas es un campo que estructuralmente está llamado al crecimiento por la evolución sectorial en marcha. Otro caso distinto es la administración propiamente dicha, en la que se puede prever una reconversión ya que, como elemento directivo que es y apoyado por las transformaciones tecnológicas de procesamiento de la información, necesite de una reestructuración que incremente en mayor proporción los niveles altos y medios-altos en detrimento de los niveles bajos, que posiblemente produzcan excedentes en los próximos años.

En realidad, esta reconversión se está produciendo silenciosamente con la disminución de oferta pública de empleo para los niveles de baja cualificación, en los que las plazas de funcionarios se sustituyen por contratos laborales que a menudo son temporales. Respecto a la posibilidad de reasignación obligatoria de personal e incluso de expulsión (excedencia forzosa), se ha dictado la Ley 22/1993, de 29 de diciembre, de medidas fiscales, de reforma del régimen jurídico de la función pública y de la protección por desempleo. En ella se faculta a las administraciones públicas la elaboración de: planes de empleo referidos tanto a personal funcionario como laboral para la óptima utilización de los recursos humanos. Aunque la aplicación concreta no se ha llevado aún adelante, quizá por prudencia o por debilidad del gobierno, su articulado parece prefigurar, mediante el eufemismo de la reasignación de efectivos, esa futura reconversión de las administraciones públicas.

En general, la contratación por parte del Estado de trabajadores administrativos (para el procesamiento de la información) de baja productividad parece poco recomendable, mientras que en los servicios de procesamiento de personas ese tipo de contratos es más compatible con su universalización. Respecto a los técnicos medios, parecen tan necesarios en la administración como en los servicios. Un caso clave es la enfermería, que parece que debiera crecer en sus tres niveles (auxiliares, ATS y grado superior). Es característico del sistema español el que no haya enfermería de grado superior.

\section{El reparto de trabajo}

El trabajo a tiempo parcial es el equivalente al contrato temporal cuando, en lugar de flexibilizar el despido, lo que se pretende es disminuir la jornada 
media para repartir el trabajo. Dado que una reducción contundente de la jornada laboral resulta complicada, ya que necesariamente afectaría a los derechos salariales de los ya ocupados, se facilita la contratación a tiempo parcial para favorecer el proceso secular de disminución de la jornada. Como forma de reparto de trabajo afecta de manera mayoritaria a las mujeres. Las características de los contratos que se han celebrado desde su nueva reglamentación parece que son mayoritariamente de baja cualificación en servicios domésticos y de limpieza. Los de menos de doce horas semanales o cuarenta y ocho mensuales se consideran marginales y tienen una menor cotización y cobertura social, por lo que su coste laboral por hora trabajada es menor.

De los tres sistemas de reparto de trabajo: la disminución de la jornada, la disminución de la vida laboral media y el aumento de rotación en los puestos, ha sido este último el que más se ha empleado como política en la España de los últimos años. La segmentación a la que ha dado lugar ha propiciado una relativa marcha atrás legislativa que parece que el sistema productivo no acepta al responder sustituyendo los CTFE desaparecidos por otros semejantes, e incluso más segregadores en derechos y que dan lugar a una mayor rotación ${ }^{23}$.

La disminución de la vida laboral típica de los varones se ha producido más de hecho que de derecho con un retraso de seis años en la edad de integración laboral durante los dos últimos decenios. El adelanto de la edad media de jubilación puede considerarse equivalente, como ya se ha apuntado al principio de este artículo. Si la situación se mantuviese, la vida laboral media de los varones habría disminuido en más de doce años respecto a la que se tenía en 1976. Es de esperar que los que en la actualidad se están integrando a trabajar a los 22 años de edad se jubilen más tarde que los que ahora lo hacen alrededor de los 60. No conviene olvidar que estos últimos comenzaron a trabajar a edades muy tempranas. En cualquier caso, parecería conveniente contrarrestar estas tendencias con políticas que tendiesen a adelantar la incorporación y a posponer la retirada. Los costes sociales que se unen a los que se producen en las biografías individuales no parecen compensar las necesidades de relevo de un sistema productivo saturado. El cambio de posición laboral de la mujer colabora en este sentido de aumentar la vida laboral media.

En resumen, la políticas que se han seguido han mostrado su alcance limitado y algunos de los elementos comentados han producido durante los dos últimos años efectos contradictorios con sus objetivos, dando lugar a un incremento absoluto y relativo de buscadores de primer empleo y a un significativo aumento de la rotación laboral a partir de 1992, que parecen indicar su insuficiencia para responder al previsible aumento de la presión laboral de los jóvenes sobre el mercado de trabajo.

${ }^{23}$ Para un análisis detallado de las formas de contratación y de sus efectos, véase Luis GARRIDO (1995), Diagnóstico sobre el paro juvenil y politicas para facilitar la entrada al primer trabajo, OIT, Ginebra. 


\begin{abstract}
Unemployment is presented as one result of the institutional manner in which Spanish society (in a European context) has incorporated improvements in quality of life. Contrary to the more widespread opinion, the author observes that in the last three decades the productive system has expelled more older than younger workers. After some reflections on the changes in the position of working women triggered by the so-called Reproductive Revolution, he goes on to examine unemployment and the occupation of those who have already completed their studies. In this respect, the author notes that the massive increase in dedication to the training of young Spaniards gives the more qualified among them a clear advantage over the rest, thus refuting the conclusions of the well-known Mediterranean Labour Integration model. The author examines the realtionship between the policy of temporary employment and young people's access to their first job, and shows that the former is a means of attaining the latter. The drastic reduction of low-level jobs represents, more than the much heralded industrial rationalisation, a genuine social rationalisation. Finally, the author outlines potential courses of action geared to improving the integration of young people on the job market.
\end{abstract}

